\title{
Organizações sociais e canais de comercialização acessados por agricultores agroecológicos: um estudo de caso na feira-livre de Chapecó/SC
}

\author{
Luiz Paulo Klock Filho ${ }^{1}$ \\ Samuel Tafernaberri Vasques² \\ Wilson Itamar Godoy ${ }^{3}$
}

\begin{abstract}
Resumo
Este trabalho apresenta as experiências de agricultores que produzem alimentos no sistema de manejo agroecológico e estão inseridos nas cadeias curtas de comercialização. $O$ objetivo do estudo é mostrar como produtores familiares, inseridos na feira central de produtos coloniais e agroecológicos do município de Chapecó, organizaram-se e comercializaram sua produção agroecológica. Verificou-se que os produtores se estruturam economicamente com a venda no canal de comercialização chamado feira-livre. Há potencialidades ao utilizar princípios da Agroecologia associados à conexão entre produtor e consumidor como estratégia para o desenvolvimento rural sustentável. Porém, é necessário que os produtores desenvolvam estratégias que fortaleçam suas organizações sociais, para, assim, aprimorar práticas de cooperação e fortalecimento do desenvolvimento local.
\end{abstract}

Palavras-chave: Agroecologia. Desenvolvimento Sustentável. Canais de Comercialização. Organizações Sociais.

\begin{abstract}
This paper presents the experiences of farmers who produce food in agroecological management system and are included in short supply chains. The objective is to show how family farmers, inserted in the central fair of regional products and agroecological of Chapecó, were organized and marketed their agro-ecological production. It was found that the producers economically structured by selling in the marketing channel called open-air market. There is potential to use principles of Agroecology associated with the connection between producer and consumer as a strategy for sustainable rural development. But it is necessary for producers to seek strategies
\end{abstract}

\footnotetext{
${ }^{1}$ Mestrando do Programa de Pós-Graduação em Desenvolvimento Regional da Universidade Tecnológica Federal do Paraná - UTFPR. luizpkfilho@gmail.com

${ }^{2}$ Mestrando do Programa de Pós-Graduação em Desenvolvimento Regional da Universidade Tecnológica Federal do Paraná - UTFPR. stvasques@hotmail.com

${ }^{3}$ Doutor em Agronomia. Professor do Programa de Pós-Graduação em Desenvolvimento Regional da Universidade Tecnológica Federal do Paraná - UTFPR. godoyutfpr@gmail.com
} 
that strengthen their social organizations, so as to enhance cooperation and the strengthening of local development practices.

Keyword: Agroecology. Sustainable development. Marketing Channels. Social Organizations.

\section{Introdução}

A discussão em torno de formas de praticar e viver a agricultura insere-se na busca da sustentabilidade do desenvolvimento, indicando um objetivo social e produtivo que busque um padrão de produção agrícola que integre, de modo equilibrado, as dimensões sociais, econômicos e ambientais. A dinâmica que envolve essas estruturas está relacionada com um novo jeito de tratar a relação homem e natureza, não tendo como meta a simples reprodução do capital.

As demandas pelo desenvolvimento, pensadas localmente, ou seja, com enfoque territorial, devem estar amparadas na substituição das formas mecanizadas de produção e de consumo em massa por opções que busquem atender aos atores sociais e ao uso equilibrado dos recursos naturais. Como explica Altieri (2001):

É possível obter, através do estudo da agricultura tradicional, informações importantes que podem ser utilizadas no desenvolvimento de estratégias agrícolas apropriadas, adequadas às necessidades, preferências e base de recursos de grupos específicos de agricultores e agroecossistemas regionais (ALTIERI, 2001, p. 26).

Nesse sentido, torna-se importante analisar quais as organizações sociais e os canais de comercialização utilizados pelos agricultores agroecológicos da feira central de produtos coloniais e agroecológicos do município de Chapecó, no estado de Santa Catarina, para entender como esses agentes mantêm-se dentro desta dinâmica e quais suas estratégias de sustentabilidade.

\section{Crise do atual modelo produtivo}

Nos últimos 50 anos, o sistema de produção da agricultura moderna, atrelada ao processo industrial de ações especializadas e simplificadas, gerou uma mudança de utilização dos agrossistemas. Desse modo, para manter a alta produtividade comercial, juntamente com o controle de pragas e doenças, os cultivos são mantidos sob o aporte artificial de nutrientes, com o uso de agrotóxicos e mecanização intensiva do solo, não considerando a sustentabilidade do manejo agrícola.

A expansão da "Revolução Verde", no início dos anos 60, trouxe um pacote tecnológico agrícola com o uso de fertilizantes, agrotóxicos, irrigação e mecanização intensiva, com aporte de rendimento em curto prazo, e, em consequência de políticas públicas direcionadas à modernização da agricultura, foi substituindo as práticas tradicionais. Este novo modelo de agricultura, gerado e difundido nos países desenvolvidos ainda nas décadas de 20 e 30 do século XX, teve sua aplicação em escala 
global, incluindo o Brasil, a partir dos anos 60.

As transformações tecnológicas foram fomentadas como única possibilidade de solucionar o problema da fome e do subdesenvolvimento no mundo. Para a grande maioria dos países periféricos, a adoção desse padrão representava mais do que autossuficiência alimentar, mas também uma oportunidade para superar o atraso tecnológico e a própria possibilidade de crescimento econômico. O padrão produtivo que se estabeleceu na agricultura brasileira foi o da passagem para a base tecnológica produtiva, sem modificar a estrutura agrária vigente, não diminuindo o poder dos latifundiários na estrutura política, social e econômica do país (PAULUS, 1999).

A opção por uma agricultura dentro das concepções capitalistas de mercado foi uma escolha da cadeia produtiva, apoiada por incentivos governamentais do Brasil - diante de um projeto nacional que estava aliado com o mercado externo, trazendo como consequência efeitos ambientais, sociais, econômicos e culturais, não sendo capaz de promover a sustentabilidade ambiental e a econômica, trazendo como consequências o aumento da erosão dos solos, a redução da biodiversidade, a poluição do solo e da água, a eutrofização de rios e lagos, alterações no clima, aparecimento de resíduos de agrotóxicos nos alimentos, contaminação de agricultores, êxodo rural, endividamento agrícola e perda dos saberes tradicionais, perpetuados entre as gerações de agricultores.

O desenvolvimento deve, por conseguinte, contemplar o mundo agrário, e, consoante à lição de Sachs (2004), faz-se necessário um novo projeto de desenvolvimento que seja capaz de articular as dimensões de crescimento econômico, de inclusão social e de sustentabilidade ambiental. Nesse sentido, é necessário pensar formas alternativas ou um novo paradigma para pensar a arena agrícola diante do cenário sincrônico de complexidades econômicas, socioculturais, territoriais, institucionais, ambientais e políticas.

O fortalecimento dos modelos alternativos acontece durante o processo de contracultura, que ocorreu em vários países, nos anos 60/70, tais como o movimento 'hippie', o ambientalismo, o feminismo, a luta contra o racismo, o movimento estudantil, que, em comum, questionavam os padrões de consumo e alimentação. Matos Filho (2004) salienta ainda que, em conjunto com os movimentos que questionavam a cultura dominante, surgiu, em 1962, no campo da agricultura nos EUA, o livro Primavera Silenciosa, de Rachel Carson, denunciando os efeitos danosos dos pesticidas no meio ambiente e contestando os padrões tecnológicos da agricultura convencional, especialmente quanto ao uso desses pesticidas e à dependência do petróleo como matriz energética.

As demandas acabaram por evidenciar os argumentos das correntes de agricultura alternativa, propiciando-lhe diversos estudos sobre o tema, de modo a resgatar a origem, as premissas, a filosofia e a prática que caracterizam os vários movimentos que ocorreram no mundo. 


\section{Agroecologia como possibilidade para crise ambiental}

Analisar as conjunturas existentes no setor agrícola está muito além de trocar a matriz convencional para a orgânica, ou até mesmo as regras que regem o mercado. O ponto crucial localiza-se nas inter-relações sociais, econômicas, culturais e ambientais que compõem o espaço rural.

Dentro dessa análise, a agroecologia surge como uma possibilidade para transformar uma sociedade cujo modelo vigente de produção agrícola é estruturado no reducionismo produtivista, para um modelo de desenvolvimento mais integrativo, participativo e sustentável. Como aponta Altieri (2001), a agroecologia fornece uma estrutura metodológica de trabalho para a compreensão mais profunda tanto da natureza dos agroecossistemas como dos princípios segundo os quais eles funcionam. Trata-se de uma nova abordagem que integra os princípios agronômicos, ecológicos e socioeconômicos à compreensão e avaliação do efeito das tecnologias sobre os sistemas agrícolas e a sociedade como um todo. Ela utiliza os agroecossistemas como unidade de estudo, ultrapassando a visão unidimensional - genética, agronomia, edafologia - incluindo dimensões ecológicas, sociais e culturais. Uma abordagem agroecológica incentiva os pesquisadores a penetrar no conhecimento e nas técnicas dos agricultores e a desenvolver agroecossistemas com uma dependência mínima de insumos agroquímicos e energéticos externos (ALTIERI, 2001, p. 23).

A busca de um desenvolvimento rural sustentável baseado na agroecologia está relacionada com a construção de sistemas locais que levem em consideração os valores das pessoas, o seu conhecimento, sua forma de organização social e as tecnologias disponíveis, em conjunto com o manejo ecológico de recursos naturais que, incorporado a uma ação social coletiva de caráter participativo, permita projetar a inclusão social em equilíbrio com a natureza.

Conforme Altieri (2001),

[...] uma abordagem 'de baixo para cima', utilizando os recursos já disponíveis: a população local, suas necessidades e aspirações, seu conhecimento agrícola e recursos naturais autóctones. Acredita-se que as estratégias baseadas na participação, capacidades e recursos locais aumentam a produtividade enquanto conservam a base dos recursos. O conhecimento local dos agricultores sobre o ambiente, plantas, solos e processos ecológicos possui uma grande importância nesse novo paradigma agroecológico (ALTIERI, 2001, p. 41).

A agroecologia nos contextos de agricultura e desenvolvimento rural sustentáveis exige um tratamento mais equitativo a todos os atores envolvidos. Como aborda Caporal (2009),

[...] a Agroecologia busca integrar os saberes históricos dos agricultores com os conhecimentos de diferentes ciências, permitindo, tanto a compreensão, análise e crítica do atual modelo do desenvolvimento e de agricultura, como o estabelecimento de novas estratégias para o desenvolvimento rural e novos desenhos de agriculturas mais sustentáveis (CAPORAL, 2009 , p. 4). 
Tal estratégia alia o conhecimento tradicional ao científico, permitindo a implementação de sistemas alternativos de agricultura, potencializadores da biodiversidade ecológica e sociocultural. Diferentemente do modelo científico convencional, os agrossistemas não podem ser fracionados ao ponto de desconsiderar as relações naturais, ou seja, os ecossistemas e seus atores sociais, impondo tecnologias padronizadas. Desses pressupostos, surge a necessidade de um novo paradigma de desenvolvimento que valorize o diálogo de saberes e o ambiente. Como colocam Floriani e Floriani (2010), a agroecologia é compreendida

[...] como um saber ambiental do campo da complexidade, isto é, fundamentado em um novo paradigma que exige a abordagem interdisciplinar e o diálogo de saberes: a criação deste corpo complexo e integrado de conhecimentos sobre os processos naturais e sociais é denominada por Enrique Leff (2001) de 'saber ambiental' que implica a construção de uma nova racionalidade e a integração interdisciplinar do conhecimento para explicar o comportamento de sistemas socioambientais complexos (FLORIANI; FLORIANI, 2010, p. 7).

O enfoque agroecológico pode ser definido como a aplicação dos princípios e conceitos da ecologia no manejo e desenho de agroecossistemas sustentáveis, num horizonte temporal, partindo do conhecimento local que, integrado ao conhecimento científico, dará lugar à construção e à expansão de novos saberes socioambientais, alimentando, assim, permanentemente, o processo de mudança de paradigma. Para Caporal (2004), através da

Agroecologia, pode-se alcançar estilos de agriculturas de base ecológica e, assim, obter produtos de qualidade biológica superior. Mas, para respeitar aqueles princípios, esta agricultura deve atender requisitos sociais, considerar aspectos culturais, preservar recursos ambientais, considerar a participação política e o empoderamento dos seus atores, além de permitir a obtenção de resultados econômicos favoráveis ao conjunto da sociedade, com uma perspectiva temporal de longo prazo, ou seja, uma agricultura sustentável (CAPORAL, 2004, p. 15).

As consequências do processo derivado pela modernização da produção agrícola não são os únicos enclaves para um desenvolvimento rural sustentável, pois este também passa pelos processos e canais de comercialização e as formas de organização social que os agricultores utilizam para manter-se na sua atividade.

Na sociedade atual, existem elementos como a expansão das grandes corporações de varejo e a concorrência de outras estruturas de comercialização na venda. Como coloca Darolt (2012),

De um lado, o advento da alimentação industrializada e o estilo de vida moderno ajudaram a afastar quem produz de quem consome. A maioria das pessoas hoje abastece sua cozinha com alimentos prontos e altamente processados. É cada vez maior o distanciamento entre o mundo rural e o urbano. A comercialização majoritária acontece em circuitos longos, tendo os supermercados como referência em detrimento das feiras de produtores por exemplo. De outro lado, cresce a procura por alimentos orgânicos e por um estilo de vida mais saudável, o que pode facilitar a reconexão entre consumidores e produtores (DAROLT, 2012, p. 13). 
Neste cenário de produção e comercialização agrícola mais vinculado com o processo de modernização dos canais de comercialização de circuitos longos, como produtores agrícolas que optaram modelos alternativos (no caso a agroecologia) enfrentam esta dinâmica?

\section{Metodologia}

Para entender o processo de modernização dos canais de comercialização de circuitos longos, a primeira etapa do trabalho foi o levantamento dos produtores agroecológicos que atuam na Feira Central (Feira de Produtos Coloniais e Agroecológicos) do município de Chapecó/SC (Figura 1).

\section{Figura 1 - Localização do Município de Chapecó/SC}

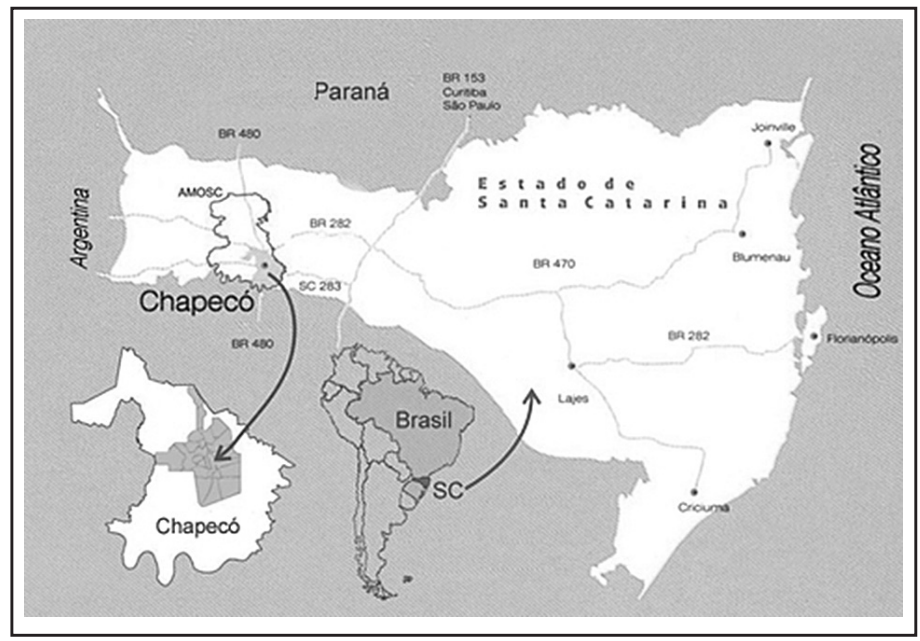

Fonte: RECHE; SUGAI (2008).

Na segunda etapa, verificado o pequeno número de famílias de agricultores certificados e inseridos nas feiras, um total de quatro, optou-se por entrevistar o grupo. No intuito de manter o contato com os responsáveis pela produção e comercialização, elegeu-se como local da entrevista o ponto de comercialização denominado Feira de Produtos Coloniais e Agroecológicos de Chapecó, situado entre as ruas Clevelândia e Rui Barbosa no bairro Centro.

A pesquisa foi realizada em novembro de 2014, quando foi aplicado um questionário semiestruturado para cada família, com perguntas abertas e fechadas, durante a realização da feira. As questões visaram obter dados referentes às atividades associativas realizadas pelos produtores e às oportunidades de comercialização de seus produtos. As perguntas foram feitas diretamente aos responsáveis das bancas, onde comercializavam diversos produtos como frutas, grãos, hortaliças, entre outros. Por fim, a última etapa constitui-se da tabulação e análise dos dados obtidos, que serão apresentados a seguir. 


\section{Resultados e discussões}

\subsection{Canais de comercialização}

As cadeias curtas de comercialização, ou seja, vendas sem intermediários, principalmente as que possuem contato direto entre o produtor e o consumidor, são referenciadas como nichos de mercado, citados por Wilkinson (2008) como segmentos que demandam confiança e contato entre produtor-consumidor, configurando-se como ótimas oportunidades de trabalho para produtores de alimentos com peculiaridade de identidade artesanal.

Na Tabela 1, todas as famílias vendem para os programas do governo federal Programa de Aquisição de Alimentos (PAA) e Programa Nacional de Alimentação Esco$\operatorname{lar}$ (PNAE) -, assim como diretamente a consumidores finais, na propriedade, entregando os produtos de casa em casa e diretamente na feira, ou seja, sem intermediadores.

\section{Tabela 1 - Canais curtos de comercialização acessados pelos produtores}

\begin{tabular}{lc}
\hline $\begin{array}{c}\text { Canais curtos de comercialização acessados } \\
\text { pelos agricultores }\end{array}$ & Número de famílias que acessam \\
\hline Feiras & 3 \\
Venda de casa em casa & 2 \\
Na propriedade & 4 \\
PAA & 2 \\
PNAE & 3 \\
Outros & 1 \\
\hline
\end{tabular}

Fonte: Elaborada pelos autores.

Conforme relato dos entrevistados, no ano de 2014, o Programa de Aquisição de Alimentos (PAA) quase não foi operacionalizado pela prefeitura, uma vez que o governo federal repassou uma quantidade muito incipiente da proposta aceita para a execução no município. Esse fato evidencia a importância da diversificação de mercados pelos produtores. Uma das famílias relatou que o Programa Nacional de Alimentação Escolar (PNAE), no ano de 2014, foi um bom instrumento de comercialização da produção agrícola.

Desta maneira, pode-se compreender que as cadeias agroalimentares locais podem contribuir positivamente para o fluxo de capital na região, uma vez que não há necessidade de importação dos produtos produzidos localmente.

A feira-livre é importante, sobretudo para agricultores que trabalham com a proposta agroecológica, como ressalta Godoy (2007, p. 368), “[...] pois além de aproximar as pessoas com interesses de troca econômicas idênticas, em que o valor é formado por uma discussão direta entre os atores, constitui-se também num palco de reprodução social". 
A perspectiva de inclusão social é fundamental para que outras famílias possam visualizar no trabalho como feirante a oportunidade de redução das desigualdades econômicas e políticas e a oportunidade de autonomia. Nesse sentido, é relevante a colocação de Vedana (2013), ao chamar a atenção para o trabalho desses sujeitos, buscando compreender essas práticas como o resultado da sistematização de um conjunto de saberes, de experiências construídas diariamente na feira.

\subsection{Renda bruta da propriedade rural}

Conforme destacado por Chiarello (2007) em seus diagnósticos, a atividade de feira, em Chapecó, era entendida como uma alternativa de geração de renda na busca da melhoria da qualidade de vida. Em seu diagnóstico, dez famílias, ou 34,49\% dos feirantes entrevistados, afirmaram que mais de $50 \%$ da renda bruta da propriedade eram obtidos através da comercialização de sua produção na feira.

Como aborda Darolt (2012),

A feira é um espaço social, cultural e educativo que propicia o desenvolvimento de relações entre consumidores e produtores ecológicos. A feira traz diversidade, resgatam valores, crenças e possibilita a troca de informações sobre alimentação, saúde e qualidade de vida (DAROLT, 2012, p. 91).

Atualmente, verifica-se que três das quatro famílias têm mais de $50 \%$ do movimento econômico bruto da propriedade rural provenientes da venda da produção na feira central. Evidencia-se que a comercialização direta ao consumidor deve ser encarada como uma atividade não agrícola que gera renda e, portanto, exige investimento de tempo em qualificação e treinamento para seu aperfeiçoamento (Gráfico 1).

\section{Gráfico 1 - Porcentagem da renda bruta da propriedade provinda da feira}

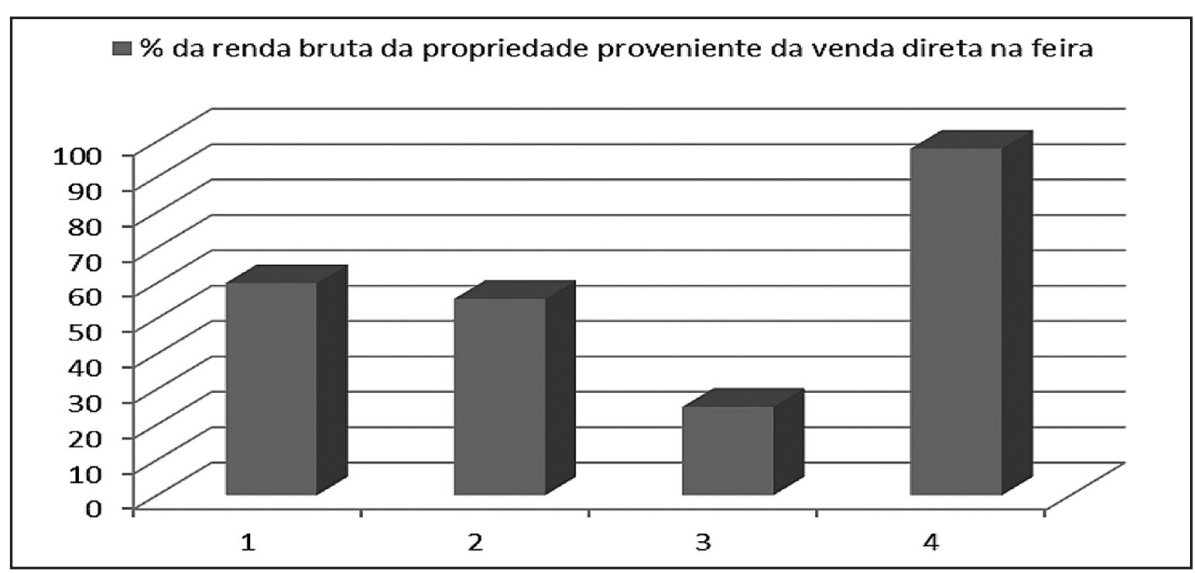

Fonte: Elaborado pelos autores.

No que se refere à porcentagem da renda bruta da propriedade, provinda dos supermercados, verifica-se, no Gráfico 2, que apenas três das famílias acessam essa modalidade de comercialização. Destas, para duas famílias, a venda nas redes 
de supermercados representa $20 \%$ da renda bruta, assim como $35 \%$ para a outra.

Gráfico 2 - Porcentagem da renda bruta da propriedade provinda dos supermercados

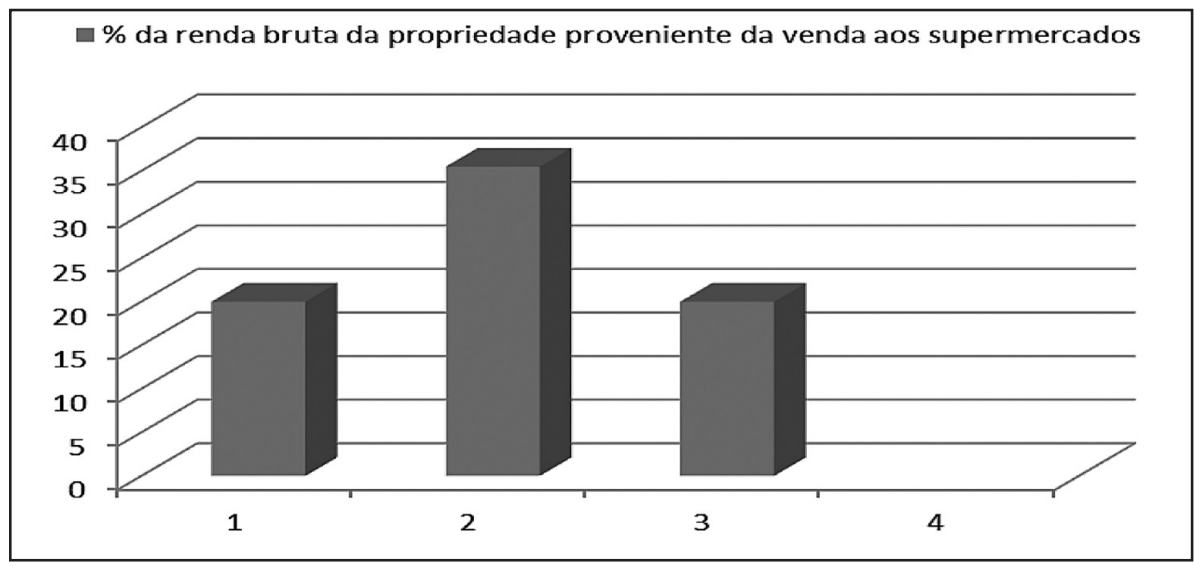

Fonte: Elaborado pelos autores.

Para grupos de agricultores organizados em cooperativas, os mercados institucionais são uma alternativa de venda direta de sua produção, pois possibilitam uma venda bruta anual em mercadorias de até 20 mil reais por DAP. No caso do PNAE, em cidades com mais de 100 mil habitantes, como no caso estudado, onde existem escolas municipais e estaduais, a oportunidade de venda aumenta, conforme o Gráfico 3, podendo-se deslumbrar como esse canal tem influência na renda bruta dos produtores entrevistados.

\section{Gráfico 3 - Porcentagem da renda bruta da propriedade provinda do PNAE}

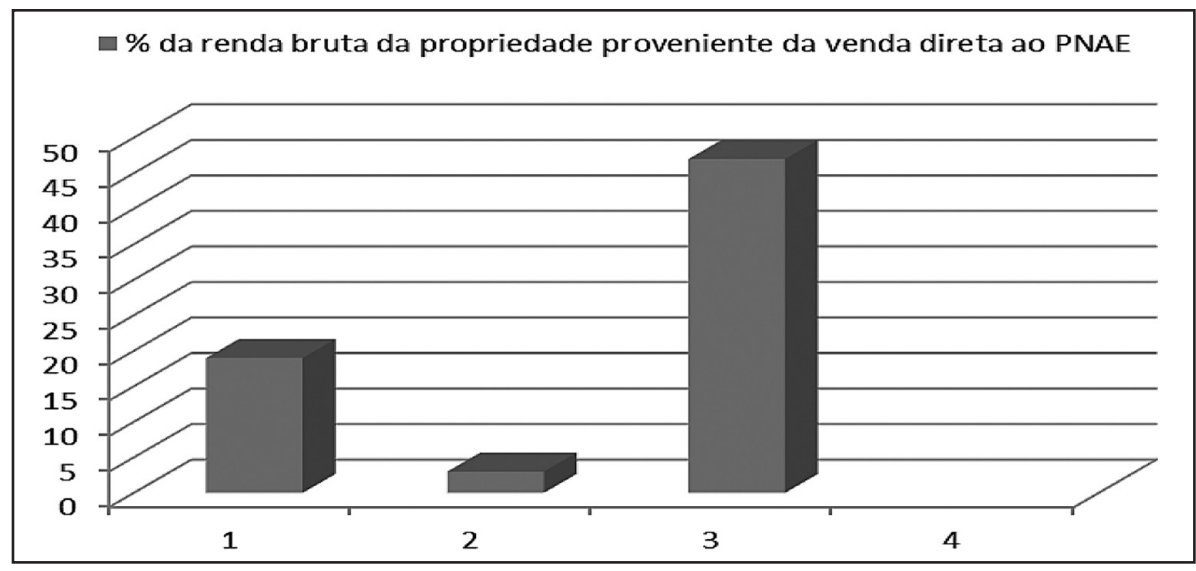

Fonte: Elaborado pelos autores. 
No tocante à organização dos agricultores, averiguou-se que uma das famílias de agricultores não é associada à cooperativa e, portanto, não comercializa para o PNAE. A representatividade da renda atribuída pelas três famílias que acessaram esta modalidade foi bastante divergente, e os relatos em percentual ficaram entre $3,2 \%$ e $47 \%$ da renda bruta da propriedade.

\subsection{Organização social dos agricultores}

A articulação entre indivíduos e grupos de uma comunidade, na construção de melhores condições de vida e aperfeiçoamento de suas potencialidades, mediante recursos que lhes permitem ter voz, visibilidade, influência e capacidade de ação e decisão, deve incidir sobre uma constante de capacidades capazes de gerar desenvolvimento.

O processo participativo está relacionado a uma postura cujas decisões não se relacionem apenas com agentes distantes da realidade vivida na comunidade, mas que aprimorem o instrumento democrático de atuação dos indivíduos nas decisões que podem interferir no seu futuro, aumentando, assim, seu grau de responsabilidade perante suas decisões.

A organização de agricultores em associações tem como fim o planejamento de atividades que oportunizem o acesso a novos mercados ou mesmo algum tipo de especialização de produção, no intuito de aumentar a pauta de produtos e evitar possíveis problemas, entre outros.

Tais associações podem constituir-se num caminho estratégico mais seguro para as mudanças, pois as dificuldades e os sucessos são compartilhados. Operacionaliza-se o dito popular de que a união faz a força. Esse mútuo comprometimento aumenta o grau de envolvimento individual e distribui responsabilidades com a totalidade das ações da unidade de produção, gerando segurança, pois atribui maior certeza às tomadas de decisões.

A organização e a mobilização dos atores sociais são fundamentais para o sucesso de qualquer tipo de empreendimento que busca o desenvolvimento local.

Para Bandeira (1999), o capital social é importante na implantação de políticas regionais que visam ao desenvolvimento regional, pois:

[...] além das iniciativas de tipo tradicional, como a implantação de infraestrutura as ações de fomento e os esforços voltados para a atração de investimentos privados, devem ser adotadas medidas que contribuam para a acumulação de capital social, fortalecendo a coesão das comunidades, promovendo a colaboração na solução de problemas comuns e estimulando os vários atores sociais a participarem ativamente da discussão das questões de interesse público (BANDEIRA, 1999, p. 21).

Nas respostas dadas na pesquisa, não foram encontradas, entre os produtores, ações que enfatizavam a importância de articulação entre os membros na possibilidade de aumentar sua dinâmica de fortalecimento de novos canais de comercialização e de organização entre eles. Muitos estão associados em cooperativas, porém ainda se mantêm ações individualizadas. 


\section{Considerações finais}

O desenvolvimento rural deve passar pelo fortalecimento de sistemas locais na busca da sustentabilidade, que deve integrar os espaços socioculturais e ambientais. As possibilidades de quebrar o paradigma do modelo convencional e buscar formas alternativas de produção, principalmente influenciadas pela agroecologia, não estão limitadas apenas à troca de insumos, mas à ação de repensar as relações de mercado, sociais e ambientais do agricultor.

Os canais de comercialização curtos, demonstrados na pesquisa como PNAE, PAA e a Feira de Produtos Coloniais e Agroecológicos de Chapecó, formam um importante espaço para a dinâmica socioeconômica dos produtores envolvidos na pesquisa, o que demonstra que a diversificação de atividades produtivas é uma significante contribuição enquanto estratégia de reprodução social e econômica para o desenvolvimento rural.

O destaque apontado no trabalho fica para a modalidade feira-livre, que é um circuito curto de comercialização e que representa a principal forma da renda bruta dos agricultores pesquisados. Nesta modalidade, a aproximação do produtor com o consumidor cria um elemento de confiança, além de ser uma importante mudança na perspectiva de consumo ao valorizar os produtos locais e ambientalmente cultivados.

No relato sobre a importância da feira como fonte de renda para os agricultores pesquisados, nota-se que é necessária uma maior capacitação dos agricultores para atuarem como feirantes. No caso de produtores agrícolas de alimentos, vale ressaltar que poucas são as pesquisas que tratam a atividade da feira como categoria de trabalho e não como mera alternativa de elevação e renda da atividade principal. Não se propõe a categorização dos feirantes de forma homogênea, mas se ressalta a importância dessa atividade de trabalho.

Outro ponto a ser observado é a forma das ações coletivas dos agricultores pesquisados. Mesmo fazendo parte da sua estratégia de venda a participação em uma cooperativa (não sendo especializada em modelos alternativos de produção) não foram vistas formas de ações conjuntas que fortaleçam a unidade entre os agricultores agroecológicos. Mesmo havendo uma associação (não formalizada), esta não foi mencionada.

A utilização de modelos alternativos não pode estar baseada somente na produção ambientalmente correta e economicamente viável, e sim deve tornar mais próximas as relações sociais, a fim de que quebrem a prática individualista instituída pelo mercado que gera desigualdades.

Como coloca Caporal (2009),

\footnotetext{
Mais do que mudar práticas agrícolas, tratar-se de mudanças em um processo político, econômico e sociocultural, na medida em que a transição agroecológica implica não somente na busca de uma maior racionalização econômico-produtiva, com base nas especificidades biofísicas de cada agroecossistema, mas também de mudanças nas atitudes e valores dos atores sociais com respeito ao manejo e conservação dos recursos naturais e nas relações sociais entre os atores implicados (CAPORAL, 2009, p. 8).
} 
As práticas sustentáveis não devem estar balizadas somente na consideração do uso racional dos recursos naturais e práticas econômicas equilibradas, mas deve envolver a aproximação dos indivíduos com suas realidades e o fortalecimento dos diversos grupos que possam quebrar essa prática individualista e o isolamento social.

Durante este processo de pesquisa, muitas sugestões de trabalho surgiram sobre esta temática. Nesse sentido, recomenda-se o aprofundamento de ações que evidenciem a importância de processos de organização social para o fortalecimento dos produtores, assim como a importância da certificação orgânica para os agricultores agroecológicos de Chapecó.

\section{Referências}

ALTIERI, Miguel. Agroecologia. A dinâmica produtiva da agricultura sustentável. 5. ed. Porto Alegre: UFRGS, 2001. p. 23-65.

BANDEIRA, Pedro. Participação, articulação de atores sociais e desenvolvimento regional. Brasília: IPEA, 1999.

CAPORAL, Francisco Roberto; COSTABEBER, José Antônio. Agroecologia: alguns conceitos e princípios. Brasília: MDA/SAF/DATER-IICA, 2004.

. Agroecologia: uma nova ciência para apoiar a transição a agricultura mais sustentáveis. Brasília: MDA/SAF, 2009.

CHIARELLO, Maralucia. Feiras Livres: uma alternativa de geração de renda aos agricultores familiares de Chapecó (SC). Trabalho de Conclusão de Curso (Graduação em Ciências Econômicas) - Universidade Comunitária da Região de Chapecó, Chapecó, 2007.

DAROLT, Moacir Roberto. Conexão ecológica: novas relações entre agricultores e consumidores. Londrina: IAPAR, 2012.

FLORIANI, Nicolas; FLORIANI, Dimas. Saber ambiental complexo: aportes cognitivos ao pensamento agroecológico. Rev. Bras. de Agroecologia, 2010, Porto Alegre, v. 5, n. 1, p. 3- 23.

GODOY, Wilson Itamar; ANJOS, Flávio Sacco dos. A importância das feiras livres ecológicas: um espaço de trocas e saberes da economia local. Rev. Bras. Agroecologia, v. 2, n. 1, fev. 2007, p. 364-368. Disponível em: < http://www.aba-agroecologia.org. br/revistas/index.php/cad/article/ view/1943/1771>. Acesso em: 10 dez. 2014.

MATOS FILHO, Altamiro Morais. Agricultura Orgânica sob a perspectiva da Sustentabilidade: uma análise da região de Florianópolis SC, Brasil. 2004. Dissertação (Mestrado em Engenharia Ambiental) - Universidade Federal de Santa Catarina, Florianópolis, 2004. 
PAULUS, Gervásio. Do Padrão Moderno à Agricultura Alternativa: possibilidades de Transição. 1999. Dissertação (Mestrado em Agrossistemas) - Universidade Federal de Santa Catarina - Centro de Ciências Agrárias, Florianópolis, 1999.

RECHE, Daniella; SUGAI, Maria Inês Sugai. A Influência do Capital Agroindustrial na Distribuição Sócio Espacial Urbana do Município de Chapecó no Sul do Brasil. $X$ Coloquio Internacional de Geocrítica. Barcelona, 2008. Disponível em: <http://www.ub.edu/geocrit/-xcol/257.htm>. Acesso em: 8 jan. 2015.

SACHS, Ignacy. Desenvolvimento: includente, sustentável, sustentado. Rio de Janeiro: Garamond, 2004.

VEDANA, Viviane. Fazer a feira e ser feirante: a construção cotidiana do trabalho em mercados de rua no contexto urbano. Horizontes Antropológicos, Porto Alegre, ano 19, n. 39, p. 41-68, jan./jun. 2013. Disponível em:

<http://www.scielo.br/pdf/ha/v19n39/v19n39a03.pdf>. Acesso em: 10 dez. 2014. 